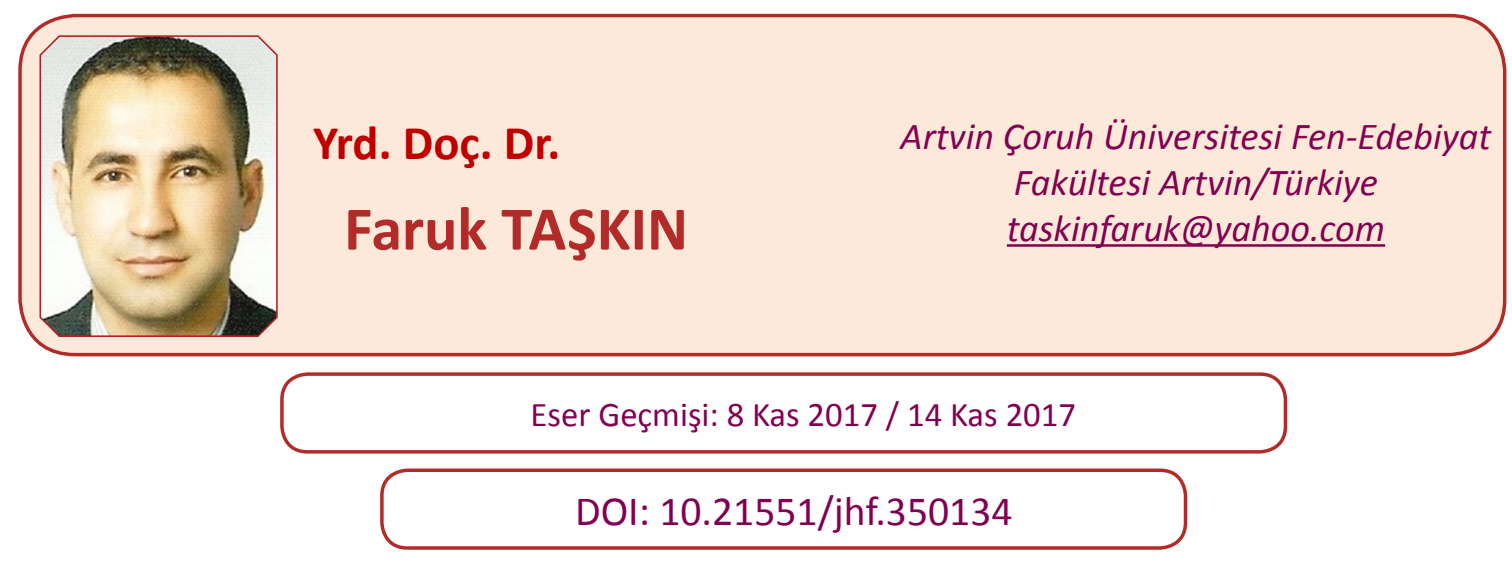

\title{
Diyarbakır'da Bir Misyoner Hastanesi: Diyarbakır Amerikan Hastanesi (1908-1915)
}

\section{A Missionary Hospital in Diyarbakır: Diyarbakır American Hospital (1908-1915)}

\section{Özet}

Amerikan Board, 1820 yılında ilk misyonerlerini Osmanlı topraklarına gönderdiği tarihten 13 yıl sonra sağlık çalışmaları için tıp misyonerlerini bölgeye göndermeye başlamıştır. İlk tıbbi misyonerler gezici hekimlik yapmaktaydı. 1880'lerden itibaren Amerikan Board, Antep, Mardin, Talas, Merzifon, Van, Erzurum, Sivas, Adana, Konya, Diyarbakır ve İstanbul gibi illerde hastane, tıp okulu, hemşire sınıfı ve eczaneler kurarak kurumsallaşma yoluna gitmiştir. Amerikan Board, Diyarbakır'da misyon teşkilatını kurması için 1851 yılında George W. Dunmore ve eşi Susan W. Dunmore’ı bölgeye göndermiştir. Sağlık çalışmaları için ise Dr. Edwin St. John Ward 1908 yılında Diyarbakır'a gönderilmiştir. Medikal çalışmalar 1908 yılında bir evin kiralanması ile Dr. Ward tarafından başlatılmıştır. Burada bir ameliyat odası, bir muayene odası, klinik laboratuvarı, birkaç kişilik bir bekleme odası aceleyle hazırlanmıștır. Misyon raporlarında klinikte kısa sürede zengin ve fakir ayırımı yapılmadan hizmet verildiği, hastalardan para alınmakla birlikte, bedava bakılan hastaların da bulunduğu belirtilmektedir. Bütün etnisite ve dinlere mensup insanlara hizmet verildiği misyon raporlarında ifade edilmektedir.

Bu çalışma Amerikan Board'ın misyonerlik aracı olarak gördüğü 1908-1915 yılında Diyarbakır'daki sağlık çalışmalarını içermektedir. Çalışma Amerikan Board'ın yıllık raporları, mikro film kayıtları, misyon katalogları ve araştırma eserlere dayanmaktadır.

Anahtar Kelimeler: Osmanlı Devleti, Amerikan Board, Misyonerlik, Diyarbakır, Hastane. 


\section{Abstract}

American Board, thirteen years later after it had sent the first missionaries to the land of Ottoman Empire, began to send the medical missionaries to the area for the health performances. The first medical missionaries worked as travel doctors. As from the 1880s, American Board, began to institutionalize by means of setting up hospitals, medical schools, nurse classes, and pharmacies in the cities such as Antep, Mardin, Talas, Merzifon, Van, Erzurum, Sivas, Adana, Konya, Diyarbakır and İstanbul. American Board sent George W. Dunmore and his wife Susan W. Dunmore to the area to set up the organization in Diyarbakır in 1851. And for the health performances, it sent Dr. Edwin St. John Ward to Diyarbakir in 1908. Medical works were commenced by Dr. Edwin through renting a house. An operating room, an examination room, a clinical laboratory, a waiting room for a few people was arranged urgently. In the mission reports it has been stated that a health service was provided without exceptions whether the patients were rich or poor in the clinic in a short time, and also while some patients were demanded for money, there were some patients who were examined and demanded for no money. It has been reported that the clinic provided health service for people from all ethnics and religious.

This study includes the health performances in Diyarbakır between the years of 1908 and 1915, which were seen as missionary tools by American Board. The study has been based upon the annual reports, micro film recordings, and mission catalogs of American Board, and searching papers.

Key Words: Ottoman Empire, American Board, Missionary, Diyarbakır, Hospital.

\section{Giriş}

27 Haziran 1810 yılında Boston'da kurulan ve Amerikan Board olarak da isimlendirilen, American Board of Commissioners for Foreign Missions (ABCFM) ${ }^{1}$ Protestan misyoner örgütlerinin en önemlilerinden biri olarak kabul edilir. Bu misyoner teşkilatı kısa sürede Çin, Hindistan, Güney Amerika, Afrika ve Hristiyanlığın çıkış noktası olan Ortadoğu'ya Protestan mezhebinin öğretilerini yaymak için misyonerler göndermiştir. Amerikan Board, Osmanlı topraklarındaki faaliyetlerine 1820 yılı baslarında başlamıştır. ABCFM üyesi olan Pliny Fisk ve Levi Parsons adlı iki misyoner, 1819 yılı Kasım ayında Boston'dan Osmanlı topraklarına doğru başlattıkları yolculuklarını 15 Ocak 1820 tarihinde İzmir'de tamamlamışlardır. ${ }^{2}$ Misyonerler temelde dini faaliyetler olmak üzere eğitim, basın-yayın ve sağlık çalışmalarını, Protestan anlayışını, hedef kitlelere ulaşmaktırlar için bir araç olarak kullanmışlardır.

Sağlık alanındaki çalışmaların insanlarla ilişki kurmada ve onları etkilemedeki önemi anlaşılınca Amerikan Board, teşkilatının bulunduğu misyon merkezlerine sağlık uzmanları göndermeye başlamıştır. Amerikan Board’ın dış ülkelere gönderdiği ilk tıp misyoneri 1919 yılında Boston'dan Hindistan'a giden John Scudder'dır. Scudder'dan önce tıp doktorlarının misyoner olarak farklı bölgelere gittikleri bilinmekle birlikte, bu misyonerler, tıp misyoner

1 Joseph L. Grabill, Protestant Diplomacy and the Near East, University of Minnesota Press, Minneapolis 1971, s. 5.

2 Frank Stone, Academies for Anatolia, University Press of America, London 1984, s. 27. 
kimliğini ve doktorluk bilgisini kullanmamışlardır. Tıp misyonerliği İncil yayıcıları arasında özellikle halkın her kesimine ulaşılması anlamında en önemli yöntem olarak kabul edilmiştir. ${ }^{3}$

Misyonerler eğitimle ulaşllamayan Müslümanlara ve özellikle uzak köylere nüfuz etmenin sağlık misyonerliği aracılığıyla mümkün olduğunu, doktor misyonerlerinin çalışmalarında görmeye başlamıştı. Sağlık faaliyetlerinin misyonerler için tarihsel ve dinsel nedenleri de bulunmaktaydı. Hristiyan inancında İsa'nın gücünü şifa yoluyla kazandı̆̆ı ifade edilir. $^{4}$

Amerikan Board, Osmanlı topraklarında faaliyetlerine başladıkları ilk dönemlerden itibaren sağlık alanında görevlendirdikleri misyonerlerine gezici hekimlik yaptırmıștır. Gezici hekimlik çalışmaları özellikle kırsal bölgelerde yapılmaktaydı. 19. yüzyılda Osmanlı Devleti'nin de içinde bulunduğu Doğu ve Ortadoğu ülkelerinde önemli sağllk problemleri yaşanmaktaydı. Özellikle salgın hastalıklar baş edilemez bir sorundu. Adı geçen bölgelerde hasta sayısının kabarık olması ve hâlâ geleneksel tedavi yöntemlerinin uygulanması, misyonerlerin sağlık çalıșmalarına daha fazla imkân sağlamıș ve onların halkla sıcak ilişkiler kurmalarını kolaylaştırmıştır. Sağlık alanındaki yetersizlik nedeniyle Osmanlı yönetiminin, misyonerlerin tıbbi faaliyetlerine çoğunlukla hoşgörüyle baktığı da ifade edilmektedir. ${ }^{5}$

Osmanlı topraklarına ilk sağlık misyonerlerinin, 1833'ten itibaren gelmeye başladıkları bilinmektedir. İlk sağlık misyonerinin Beyrut'a gelen Dr. Asa Dodge olduğu belirtilmektedir. Dr. Dodge, Kudüs'te bulunduğu 1835 yılında tifüse yakalanmış ve vefat etmiştir. ${ }^{6}$ Illk misyoner doktorlar, bölgede gezici doktor olarak çalışmaktaydı. ${ }^{7}$ Amerikan Board, 1835'te Dr. Asahel Grant'ı bütün misyon merkezlerini sağlık olanaklarıyla donatmakla görevlendirmişti. ${ }^{8}$

Misyoner doktorlar bölgeye ilk geldiklerinde mesleklerini icra etmek için bir hastane ortamı olmadığından evlerini klinik olarak kullanmaktaydılar. Bu doktorlar aynı zamanda yerli bölge halkından yetenekli olanları da eğiterek yardımcıları yapmışlar ve zamanla bu yardımcı kişiler tecrübelerini kullanmışlardır. Bu șekilde eğitim verme konusunda Dr. Grant, Dr. Henry S. West, Dr. Azariah Smith uygulamanın öncülleri olmuşlardır. Zamanla hastane kurma düşüncesi gelişmiş ve 1880'lerden itibaren daha donanımlı hastaneler kurmaya başlamışlardır. ${ }^{9}$ Birinci Dünya Savaşı'ndan önce Merzifon, Sivas, Talas, Konya, Antep, Adana, Harput, Van, Erzurum, Mardin ve Diyarbakır gibi bölgelerde misyonerler hastaneler kurmuşlardır. ${ }^{10}$

3 J. H. Franklin, Ministers of mercy, , Pilgrim Press, New York 1919, s. 3.

4 The Nursing in Mission Stations, Trained Nurses Needed Immediately for Rlissionarp Service, The American Journal of Nursing, Vol. 11, No. 3. (Dec., 1910), ss. 190-191.

5 Uygur Kocabaşoğlu, Anadolu'daki Amerika, İmge Kitabevi, Ankara 2000, ss. 127-128.

6 James L. Barton, Daybreak in Turkey, The Pilgrim Press, Boston 1908, s. 205.

7 David B. Eddy, What next in Turkey Glimpses of the American Board's Work in the Near East. The American Board, Boston Mass. 1913, s. 133.

8 Seçil Akgün, Kendi Kaynaklarından Amerikalı Misyonerlerin Türk Sosyal Yaşamına Etkisi (1820-1914). X. Türk Tarih Kongresi'nden Ayrı Basım, TTK Basımevi, Ankara 1994, s. 2139.

9 The Orient, "Medical Missionary Work", vol. IX. Extra Bible House, March 8, Constantinople 1922, s. 24.

10 Faruk Taşkın, Kendi Kaynaklarında Amerikan Board'ın Türkiye'deki Săgllk Faaliyetleri (1833-1923), Mersin Üniversitesi Sosyal Bilimler Enstitüsü Yayınlanmamış Doktora Tezi, Mersin 2015. 


\section{Misyonerlerinin Diyarbakır'a Gelişi}

Tarihsel süreçte birçok uygarlığa ev sahipliği yapan Diyarbakır Osmanlı döneminin önemli yerleşim merkezlerinden biri olmuştur. Söz konusu coğrafyada farklı etnik ve dini grupların varlığı tarihsel süreç içerisinde devam edegelmiştir. Burada yaşayan başta Süryaniler, Ermeniler ve Nasturiler, misyonerlerin hedef kitlesi olmuştur. Diyarbakır'daki Amerikan misyonerlerinin hedefinde de Ermeniler, Nasturiler, Keldaniler ve Süryani Kadim Ortodokslar (Yakubi) bulunuyordu. ${ }^{11}$

Amerikan Board'ın Doğu ve Güneydoğu Anadolu'ya yönelik ilgisi Elia Smith ve Henry O. Dwight'ın 1830 yılında İstanbul'dan başlayıp, Ankara, Erzurum Kars ve Tiflis'e uzanıp, oradan Erivan, Tebriz ve Urmiye'ye kadar yaptıkları araştırma gezisinin sonucunda meydana geldiği belirtilmektedir. Her iki misyoner de hem Nesturîler ve hem de Ermenilere yönelik misyon çalışmasının gerekliliğini hazırladıkları raporlarında misyon merkezine iletmişlerdir. Amerikan Board, 1835 yılında ağırlıklı olarak Musul, Diyarbakır bölgesi ile İran'ın Urumiye bölgesinin oluşturduğu üçgende yaşayan Nasturîlere yönelik bir misyon kurma kararı almıştır. Hakkâri bölgesindeki Nasturîler arasında çalışmak üzere, doktor olmasının insan ilișkilerinde ve bölgedeki seyahatinde ișleri kolaylaștıracağı düşünüldüğünden Dr. Asahel Grant seçilmiştir. Dr. Grant, 1839 yazında, İstanbul'dan gelecek misyoner Henry A. Homes ile buluşarak Hakkâri bölgesine doğru yola devam etmek üzere Diyarbakır'a geldi. Grant'ın ziyaret ve değerlendirmelerinin bir sonucu olarak 1841 yılında Amerikan Board, Hakkâri bölgesinde "Bağımsız Nasturi Misyonu"nu kurmuştur. ${ }^{12}$

Dr. Grant'tan sonra Urumiye misyonunu, 1849'da bölgeye gelen Justin Perkins devralmıştır. Bundan sonra Diyarbakır merkezli çalışmalar Musul'a yönelik faaliyetlerin ikmal üssü olarak düșünülmüștür. Ancak Hakkâri-Botan Nasturîleri 1840’lı yıllarda bölgedeki Kürt Beyleri'nin saldırıları sonucu büyük oranda öldürüldüler ve sağ kalanlar da Musul bölgesine kaçınca, Amerikan Board, Nasturîlere yönelik çalışmalarını durdurdu. ${ }^{13}$ Nasturî Misyonu'nun kapanmasından sonra 1850'de Diyarbakır, Asurî (Keldani, Süryani, Yakubi, Nasturi topluluklarına verilen genel isim) misyonunun kurulması kararlaștırılmıștır. Amerikan Board, Diyarbakır'da misyon teşkilatını kurması için 1851 yılında George W. Dunmore ve eşi Susan W. Dunmore'ı bölgeye göndermiştir. Dunmore çifti, bir süre Antep'teki misyon merkezinde Türkçe öğrenmek için kalmış ve aynı yıl Diyarbakır'a geçmişti. ${ }^{14}$ Bir yıl sonra Henry Lobdell eşi ile beraber Antep ve Urfa üzerinden Diyarbakır'a gelerek misyon çalışmalarına katıldı. ${ }^{15}$ Daha sonra bu guruba misyoner Augustus Walker katılmıştır. ${ }^{16}$ Bu süreçte kilisenin kurulduğu ve şehirde 1859 sonunda 61 kişinin Protestan olduğu belirtilmektedir. Diyarbakır'dan ayrılan İngiliz Konsolosu W. R. Holmes'in evi ibadet ve eğitim amaçlı kullanılmak üzere misyonerlerce 1000 dolara satın alınmıştır. 1864 yılında Diyarbakır genelinde misyoner okul sayısının

11 Resul, Çatalbas, "Diyarbakır'da Misyonerlik Faaliyetlerinin Tarihi”, İstanbul Üniversitesi Illahiyat Fakültesi Dergisi, 29, 2013, s. 110.

12 Esra, Danacıoğlu, “Diyarbakır'da Amerikan Misyonerleri”, Diyarbakır: Müze Şehir, (Haz. Ş. Beysanoğlu-M. S. Koz-E. N. İşli), YKY, İstanbul 1999, s. 166.

13 Danacioğlu, a.g.m. s. 168.

14 ABA, Memorial Record for George W. Dunmore, an Employee of the American Board, İstanbul.

15 Oktay.. Bozan, “Osmanli Döneminde Amerikan Misyonerlerinin Diyarbakır Vilayeti”ne Gelişi ve Faaliyetleri”, Dicle Üniversitesi Sosyal Bilimler Enstitüsü Dergisi, 7/13, Nisan, 2015, 341.

16 ABA, Memorial Record for Augustus Walker, an Employee of the American Board, İstanbul. 
6'ya ulaştığı, buradaki öğrencilerin sayısının da 178 olduğu ifade edilmektedir. ${ }^{17}$ Amerikan misyonerlerinin Diyarbakır merkezde iki Çüngüş’te kız-erkek ve Palu'da erkek Ermeni yetim çocuklar için yetimhane açmışlardır. ${ }^{18}$

\section{Diyarbakır Amerikan Hastanesi}

Diyarbakır'da sağlık çalışmalarının başlaması aslında misyonun bölgede kurulmasıyla başlamıştı. Amerikan Board'ın bölgeye gönderdiği ilk misyonerlerden David H. Nutting ve Henry Lobdell tıp eğitimi almış misyonerlerdi. Dr. David H. Nutting ve eşi 1854 yılında Diyarbakır'a geldi. Dr. Nutting, hekimlik bilgisini misyoner çalışmalarında etkin bir şekilde kullandı. Dr. Nutting, Diyarbakır'daki ilk yılında 1350 hastayı dispanserde tedavi etmiş ve ayrıca hastaların evlerine 350 ziyaret yapmıştır. Dr. Aynı zamanda Diyarbakır'daki Pazar okulunun da sorumlusuydu. Dr. Nutting 1859 yılında Şehirden ayrılıncaya kadar çalışmalarını sürdürmüştür. ${ }^{19}$

Yine Dr. Lobdel de doktorluk bilgisini kullanarak Hristiyanların yanı sıra Müslümanlarla da iletişim kurmaktaydı. Misyonerlik çalışmasının yanı sıra sağlık çalışmalarını da yürüten Dr. Lobdell'in günde yaklaşık 100 hastaya baktığı belirtilmektedir. ${ }^{20} 1855$ yılında Amerikan Board'ın Musul'a atadığı Dr. Henry B. Haskel ilk yılını Diyarbakır'da geçirmiştir. ${ }^{21} \mathrm{Bu}$ dönem ve uzun bir süre sonrasında yapılan sağlık çalışmaları gezici hekimlik şeklinde veya ayakta tedavi dediğimiz ve geçici müdahalelerin yapıldığı dispanserde yapılmaktaydı. Bu dispanserler misyonerlere ait evlerdi. Doktorlar, tıp bilgilerini misyon çalışmalarında kolaylık sağlamak için kullanmaktaydı.

Amerikan Board'ın Diyarbakır'da kurumsal olarak sağlık çalışmalarını yürütmesi ancak 1908 yılından itibaren uygulanmaya konulacaktır. Aslen Ermeni olan ve Amerika'da yaşayan Aslan Sahagian'ın 15.000 dolar parasını eğitim ve Diyarbakır'daki hastanenin yapılması için miras bırakmıştır. ${ }^{22} \mathrm{Bu}$ kaynağın değerlendirilmesi doğrultusunda Amerikan Board, 1907 yılında Diyarbakır'da sağlık çalışmaları için Dr. Edwin St. John Ward’ı görevlendirmiştir. Dr. Ward, Osmanlı devletinde doktorluk yapabilmek için bir süre Paris'te kalarak Fransızca öğrendi. Misyoner doktorlar batının tıp eğitimiyle yetişmiş olsalar da Osmanlı devletinde mesleklerini icra etmeden önce İstanbul'da yeterlilik sınavını Türkçe ya da Fransızca olarak başarmak durumundaydı. ${ }^{23}$ İstanbul'daki sınavı geçen Ward, bir yıl Antep'te çalıştı. Daha sonra çeşitli dönemlerde Viyana, Berlin, Paris ve Strazburg gibi yerlerde de çalışır. Dr. Ward ve eşi Türkiye'ye gelince bir süre Antep'te kalarak Türkçe öğrenmişler ve Dr. Fred D. Shepard'dan da misyon çalışmaları hakkında bilgi almışlardı. Antep'ten sonra Harput'a geçen Dr. Ward ve eşi yaz ayını burada geçirdiler. Ekim ortasında Harput'tan ayrılarak tekrar Diyarbakır'a geldiler.

17 Çatalbaş, a.g.m. s. 121.

18 Hatip Yıldız, "II. Abdülhamit Döneminde Diyarbakır Vilayetinde Açılan Yetimhaneler ve Vali Mehmed Halid Beyin Vilayette Misyonerliği Önleme Çabaları” Dicle Üniversitesi Ziya Gökalp Ĕ̌itim Fakültesi Dergisi, 14, 2010, 110.

19 ABA, Memorial Record for David H. Nutting, an Employee of the American Board, İstanbul.

20 Bozan, a.g.m. s. 344.

21 ABA, Memorial Record for Henry B. Haskel, an Employee of the American Board, Istanbul.

22 Julius Richter, J., A History of Protestant Missions in the Near East, London 1910, s. 157.

23 Barton, a.g.e. s. 63. 
Misyon raporlarında Diyarbakır'da medikal çalışmalarının, bir evin kiralanarak 1908 yılında Dr. Ward tarafından başlatıldığı belirtilmektedir. ${ }^{24}$ Daha önceden bekçi evi ve birkaç yıl kızlar için yetimhane olarak da kullanılan ev (Walker Evi), klinik olarak kullanılmak üzere açıldı. Burada bir ameliyat odası, bir muayene odası, tedavi odası, klinik laboratuvarı, birkaç kişilik bir bekleme odası aceleyle hazırlanmıştır. Bu mekân tatmin edici olmasa da başlangıç için yararlı görülmüştür. ${ }^{25}$

Hastane malzemeleri Amerika ve İngiltere'den sipariş edilmiştir. Başlangıçta hastanede Dr. Ward ile anestezi ve pansuman işlerine yardımcı olan Nishan Bakalian çalışılmaktaydı. Hasta sayısının artması üzerine, sargı işlerine ve klinik çalışmalarına bakacak bir hemşireye ihtiyaç duyulmuştu. Ayrıca kadın hastaların erkek doktora tedavi olmak istememeleri de ayrı bir sorundu. Bu sorunu çözmek için birkaç yıl Merzifon Hastanesi ve İstanbul'da çalışmış, eğitimli bir ebe olan Bayan Priscilla Baldwin Türk yetkililerden de izin alarak Diyarbakır'a gelmiștir. ${ }^{26}$ Bayan Baldwin, Merkezi Türkiye Koleji'nden mezun olmuş bir Diyarbakırlı idi. Bayan Baldwin, hemşire görevinin yanında doktorun tercümanlığını da yapmaktaydı. ${ }^{27}$

Misyon raporlarında hastanede kısa sürede zengin ve fakir ayırımı yapılmadan hizmet verildiği, hastalardan para alınmakla birlikte, bedava bakılan hastaları bulunduğu belirtilmektedir. Hastalar şehir merkezinden ve çevre köylerden gelmekteydi. Bütün etnisite ve dinlere mensup insanlara hizmet verildiği misyon raporlarında ifade edilmektedir. ${ }^{28}$ Gözlerinde problemi olan zengin bir Türk'ün kendilerine gelmeden önce birçok doktora gittiğini ancak tedavisinin yapılamadığını, misyoner hastanesinde bir iki operasyondan sonra hastanın, sağlığına kavuştuğu ifade edilmektedir. Bu kişi daha sonra hastaneye yiyecek ve çiçeklerle gelerek şükranlarını iletmiş ve hastaneye tedavi için başka kişileri de getirdiği belirtilmektedir. Ağır hasta olan şehirdeki bir paşanın oğlunun tedavi edilerek kurtarıldığı da misyon raporlarında belirtilmektedir. Diyarbakır'daki yerel şartlar, siyasi, sosyal ve Protestan Kilisesi'nin statüsü yüzünden doktorun sıradan bir tıp pratisyeni gibi görev yaptığı iddia edilmektedir. ${ }^{29}$

Aşağıdaki tabloya bakıldığında diğer bölgelerde olduğu gibi Diyarbakır bölgesinde de göz hastalıklarının yoğun olduğunu görmekteyiz. Hastanede tedavi olanlar içerisinde Ermeniler yoğunluğu oluşturmaktadır. İkinci sırada ise Türkleri görmekteyiz. Dinsel olarak ise Gregoryen Ermeniler tedavi olanlar içerisinde çoğunluğu oluşturmaktadır. 1909 tarihine kadar 12 farklı etnisiteden kesim hastaneye başvurmuş, 1351 yeni hasta tedavi edilmiş ve 126 operasyon yapılmıştır. ${ }^{30}$

24 ABA, ABCFM (1917-1922), 1921 No: 086.

25 Reel 703, No: 480.

26 Reel 703, No: 481.

27 ABA, Memorial Record for Edwin S. Ward, an Employee of the American Board, İstanbul.

28 Reel 703, No: 482.

29 Reel 703, No: 482.

30 The American Board of Commissioners for Foreign Missions, the Year Past and The Year to Came, Report of the Prudential Committee for the Home Department, 1908-1909, Boston 1909, s. 77. 


\begin{tabular}{|c|c|}
\hline $\begin{array}{l}\text { (30 Haziran 1908-15 Haziran 1909) } \\
\text { Hastanede Yapılan Tedaviler }\end{array}$ & \\
\hline Yeni hasta sayıs1 & 1351 \\
\hline Tedavi say1s1 & 6424 \\
\hline Yardımcılar Tarafindan Yapılan & \\
\hline Göz muayenesi dâhil yapılan tedaviler & 4323 \\
\hline Ameliyat ve genel yaralar & 1700 \\
\hline Doktor tarafindan yapılan tedaviler & 401 \\
\hline Toplam & 6424 \\
\hline Ameliyatlar & \\
\hline Önemli ameliyat & 111 \\
\hline Küçük ameliyat & 15 \\
\hline Toplam & 126 \\
\hline Ocak 1909'a Kadar Dışarıya Yapılan Ziyaı & \\
\hline Ücretli & 522 \\
\hline Yarı Ücretli & 37 \\
\hline Ücretsiz & 215 \\
\hline Toplam & 774 \\
\hline
\end{tabular}

Kaynak: ABCFM, Reel 703, No: 484.

Aşağıdaki tabloda etnisite olarak Ermenilerin tedavi olanlar içerisinde en yüksek sayıya sahip olduğunu görülmektedir. İnanç olarak da Gayrimüslimlerin çoğunluğu oluşturduğu anlaşılmaktadır.

Tablo 2: Diyarbakır Amerikan Hastanesi'de Tedavi olanların Etnisite ve Dinsel İstatistikleri (30 Haziran 1908-15 Haziran 1909)

\begin{tabular}{|l|l|l|l|}
\hline Etnisite: & Din: & \\
\hline Türk & 318 & Müslüman & 371 \\
\hline Kürt & 53 & Protestan Ermeni & 128 \\
\hline Ermeni & 787 & Katolik Ermeniler & 64 \\
\hline Süryani & 129 & Gregoryen Ermeniler & 593 \\
\hline Keldani & 29 & Protestan Süryaniler & 28 \\
\hline Yahudi & 10 & Katolik Süryaniler & 12 \\
\hline Fransız & 2 & Jacobite Süryaniler & 95 \\
\hline Rum & 1 & Keldaniler & 30 \\
\hline Arap & 1 & Yahudiler & 10 \\
\hline İran & 1 & Rumlar & 7 \\
\hline Misır & 1 & Yezidi & 1 \\
\hline Toplam & 1339 & Toplam & 1339 \\
\hline
\end{tabular}

Kaynak: ABCFM, Reel 703, No: 484. 
Yapılan çalışmaların neticesinde misyonerlerin sağlık çalışmaları için, daha büyük bir binaya ihtiyaç olduğu fikri oluşmuştur. Tıbbi misyonerliğin başarısı için bunun gerekliliği

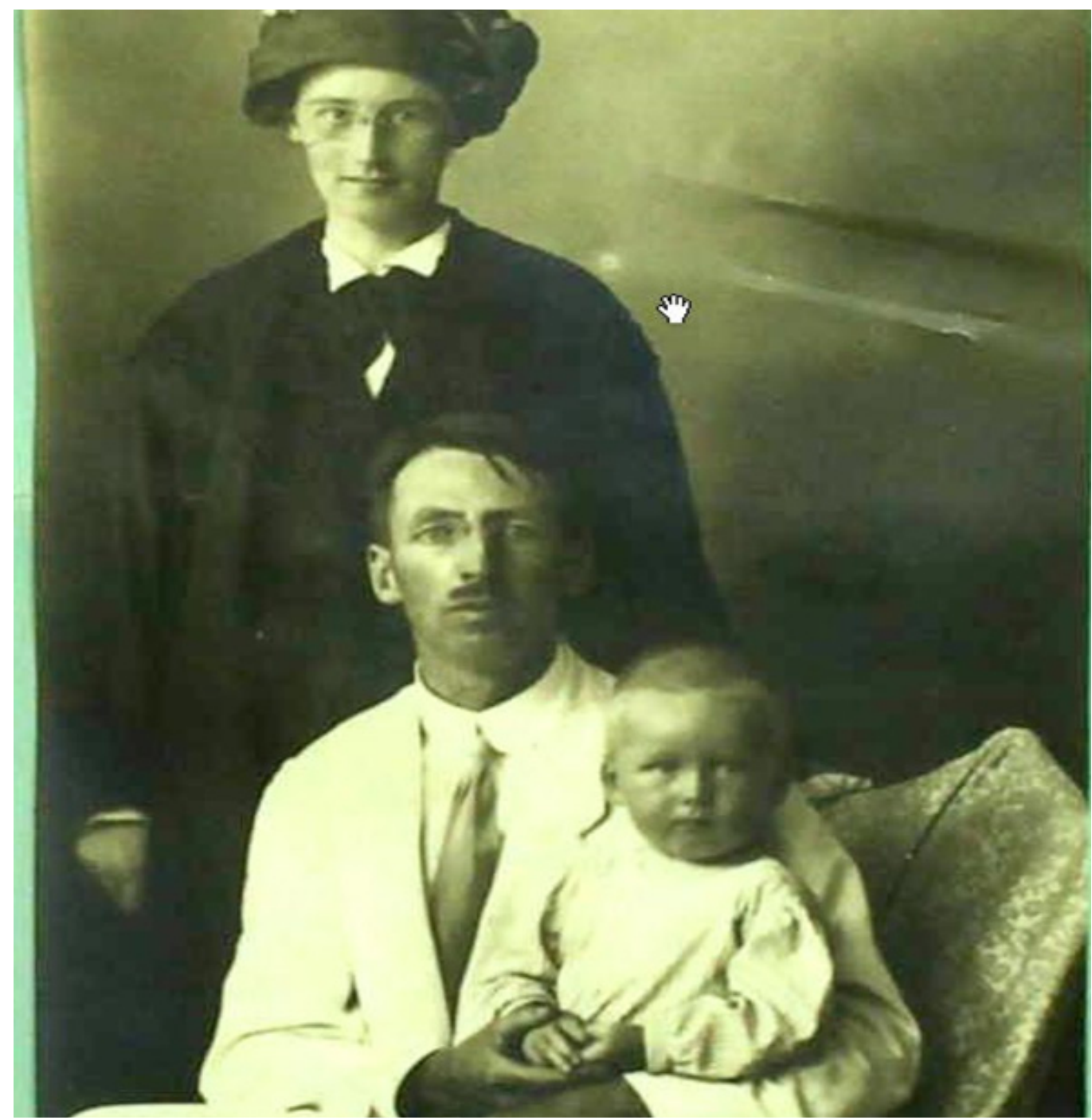

Dr. Floyd O. Smith (1885-1961)

Kaynak: American Research Institute in Turkey-Istanbul.

vurgulanmaktadır. Özelikle bütün araç ve gereçlerin bulunduğu bir ameliyat odası, daha iyi bir laboratuar, muayenehane, hastaların ameliyat sonrası kalacağı bir yer ve eczane isteği belirtilmiştir. $^{31}$ Diyarbakır'daki yoksullar için Amerika'daki bir Ermeni tarafından 3.49 lira misyonerlere gönderilmiş ve hemşirenin desteklenmesi için de yıllık 80 lira verileceği belirtilmiştir. ${ }^{32}$

Aşağıdaki tabloya bakıldığında Diyarbakır sağlık misyonun gelir gider bütçesi denk olarak görülmektedir. Gelirler içerisinde Amerikan Board'ın yardımı en yüksek gelir kalemini oluşturmaktadır. Giderler içerisinde de faturalar 173.65 ile en yüksek harcamayı oluşturmaktadır. 
Tablo 3: Diyarbakır Misyonu Sağlık Bütçesi

(1 Temmuz 1909-1 Ocak 1910)

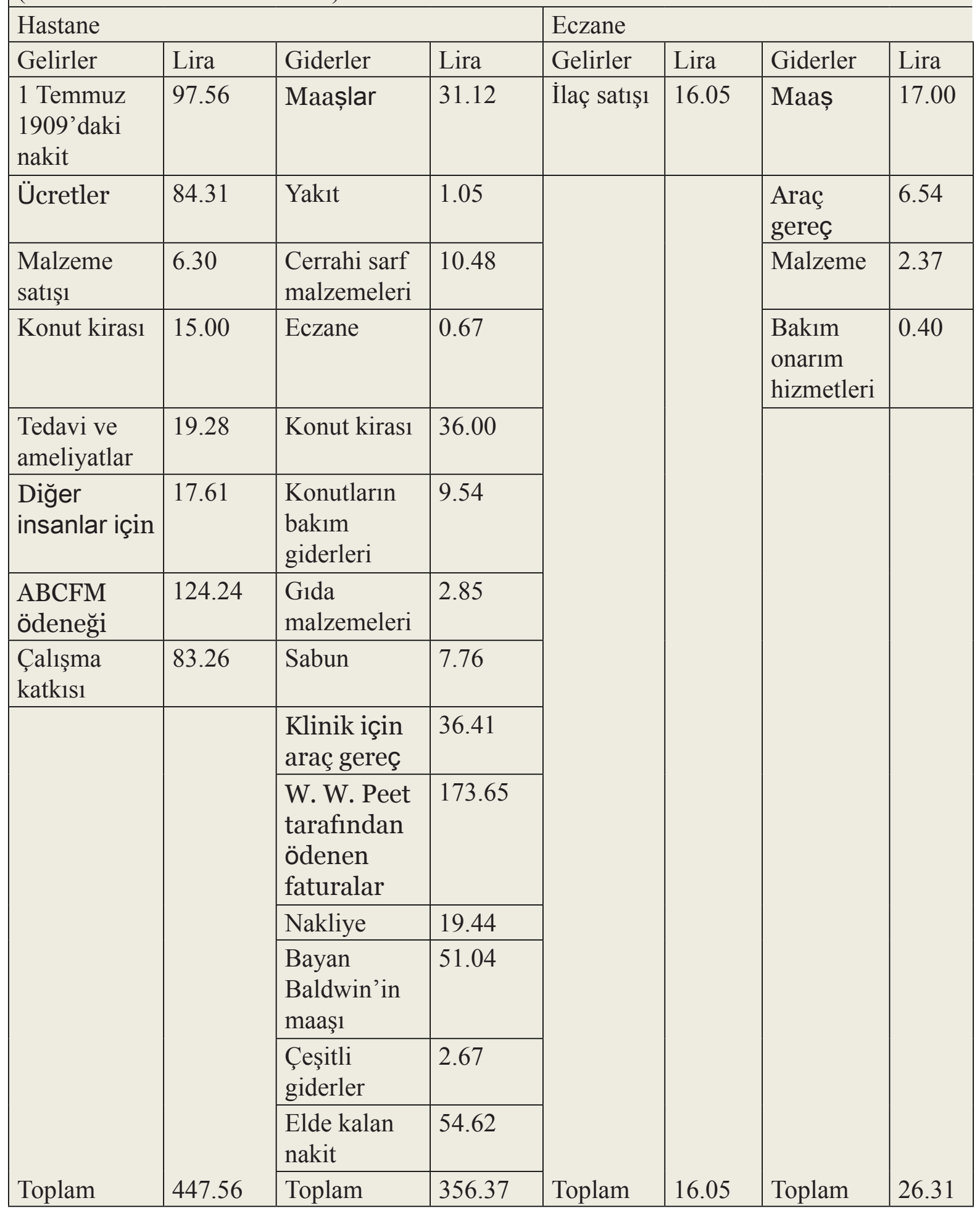

Kaynak: ABCFM Reel 706, No: 486. 


\section{1. Sağlık Çalışmalarının Sona Ermesi}

Dr. Ward, 1910 yılında şehrin dışında bir yerde hastane açmayı planladıysa da Beyrut'a Tıp Fakültesinde ders vermesi için çağrılmış ve Mayıs 1911 yılında Diyarbakır'dan ayrılmıştır. ${ }^{33}$ Misyon merkezi, 1910-1914 tarihleri arasında doktor yokluğundan dolayı faaliyetlerine ara vermek zorunda kalmıştır. ${ }^{34}$

Amerikan Board, bölgede tekrar sağlık çalışmalarını başlatmak için arayışlara girmiştir. Çalışmalar neticesinde Amerikan Board, sağlık çalışmalarını yürütmek için Iowa Üniversitesi Tıp Bölümü'nden 1912 yılında mezun olan Dr. Floyd O. Smith’i bölgeye gönderme kararı aldı. Dr. Smith ve eşi ilk altı aylarını Fransa'da dil öğrenmek için geçirdikten sonra İstanbul'a gelerek burada doktorluk mesleğini icra etmek için diğer misyoner doktorların yaptığl gibi yeterlilik sınavına girmiş ve çalışma belgesini almıştır. Dr. Smith, Diyarbakır'a geçmeden önce bir süre Antep'te kalarak Türkçe öğrenmiștir. Hastalarla iletişim kuracak kadar dil öğrenen Dr. Smith, Antep'ten Diyarbakır'a geçerek medikal çalışmaları başlatmıştır. ${ }^{35}$

1914 yılının Haziran ve Ekim aylarında Harput'ta da bulunmuştur. 1914-15 kışında Diyarbakır'da tifüs salgının patlak verdiği Dr. Smith salgınla ilgili görüşlerini șehrin valisine ilettiyse de konu ile ilgilenilmediğini ifade eder. Dr. Smith'in Diyarbakır'a geldiği dönem Birinci Dünya savaşının da patlak verdiği sürece denk gelir. Bu dönem aynı zamanda Ermeni sorunun da yaşandığı yıllardır. Dr. Smith, Ermenilerle olan ilişkisinden dolayı hükümet tarafından sınır dışı edilmesi kararı alınır ve Halep'e gönderilir. Bu dönemde cerrahi operasyonlar az olsa da hastalar neredeyse her gün tedavi için Diyarbakır'daki kliniğe gelmekteydi. Malzeme eksikliği ciddi sorunlara neden oluyordu. Bazı malzemeler yerel doktorlardan temin edilmekteydi. Düzenli bir hastane binasına ihtiyaç vardı ancak bunun gerçekleşme olasılığı yoktu. ${ }^{36}$

$\mathrm{Bu}$ süreçte misyon çalışmaları da gelişmelerden olumsuz etkilenmiştir. Misyonun bazı çalışanlarının tutuklanması misyon faaliyetlerini olumsuz etkilemiştir. Daha sonra da Diyarbakır merkez olma özelliğini kaybetmiş ve Harput misyon merkezine bağlanmıștır. ${ }^{37}$ Böylece Amerikan Board'ın Diyarbakır'daki sağlık çalışmaları 1915 yılında son bulmuştur.

\section{Sonuç}

Amerikan Board misyonerlerinin Osmanlı topraklarına ayak bastığı 1820 yılından 13 yıl sonra sağlık misyonerlerini göndermesi, yeni bir misyonerlik uygulamasının da başlangıcını oluşturmuştur. 1830'lardan itibaren Amerikan Board, eğitimli misyoner hekimlerini ülkenin farklı bölgelerine göndererek misyon çalışmalarında etkili olmaya çalışmıștır. Okullarla ulaşılamayan bölgelere ve toplumlara sağlık çalışmalarıyla ulaşılmak istenmiştir. Misyonerler, özellikle gezici hekimlik sayesinde ülkenin en uç köşelerine gitme olanağı bulmuşlardır. Yine

33 ABA, Memorial Record for Edwin S. Ward, an Employee of the American Board, İstanbul.

34 The One Hundred and Third Annual Report of the American Board of Commissioners for Foreign Missions, Together with the Minutes of the Meeting Held at Kansas City, Missouri October 26-28, Boston 1913, s. 93.

35 Eddy, a.g.e. s. 120 .

36 The One Hundred and Fifth Annual Report of the American Board of Commissioners for Foreign Missions, Together with the Minutes of the Meeting Held at Nev Haven, Connecticut, October 26, Boston $1915,111$.

37 ABA, ABCFM (1917-1922), 1921, No: 086. 
uzak köylerden de hastanelere hastalar gelerek tedavi olmuşlardır.

Diyarbakır'da Amerikan Board'ın sağlık çalışmaları bölgeye atanan ilk misyonerlerle başlatılmışsa da kurumsal olarak etkinlik göstermesi 1908'lerden sonra başlamıştır. Hastane bütün etnisitelere açık olarak çalışmalarını sürdürmüştür. Tedavi edilen hastalar arasında Ermeniler çoğunluğu oluştursa da Türk, Kürt, Süryani, Keldani, Yahudi, Fransız, Rum, İran ve Mısır uyruklular da hastaneden yararlanmışlardır.

Misyoner doktorlar hastanenin yanı sıra zaman zaman çevre yerleşim birimlerine de giderek sağlık çalışmaları yapmaktaydılar. Ayrıca hastanede tedavi gördükten sonra evlerine dönen hastaların evlerine kadar giderek daha yakın ilişkiler kurmuşlardır. Kadın hemşirelerin mahallelere ziyaretler yaparak ve özellikle eski hastaları bularak onlarla görüştüğü ve her türlü yardımların yapıldığı raporlarda ifade edilmektedir.

Hastane tedavi görenlerin ekonomik durumuna göre ücretlendirme yapmaktaydı. Ücretlendirme tam, yarım ve ücretsiz olarak yapılmaktaydı. Ücretsiz tedavi edilen hastaların giderleri Amerika'dan gönderilen yardımlarla karşılanmaya çalışılmıştır. Sağlık çalışmaları bir evin hastaneye dönüștürülmesiyle bașlamıștı. Her ne kadar daha donanımlı bir hastane kurulması düşünülmüşse de dönemin şartlarından dolayı girişimler sonuçsuz kalmıştır. Diyarbakır Amerikan Hastanesi netice itibariyle bir misyoner hastanesidir. Bu misyoner örgütün çalışmalarında Ermeniler önceliği oluşturmaktaydı. Gregoryen Ermenilerin Protestanlaştırılmasında bir nevi başarılı da olmuşlardı. Ancak I. Dünya savaşının getirdiği koşulların neticesinde bölgedeki Ermenilerle Osmanlı Devleti'nin yaşadığı sorun bölgede misyon çalışmalarını da etkilemiştir. Özellikle Misyoner Dr. Floyd O. Smith'in isyancı Ermenilerle olan ilişkisi neticesinde misyoner çalışmalarının sürdürülmesi artık imkânsız hale gelmiş ve 1915 yılında sağlık çalışmalarının da sonu olmuştur.

\section{Kaynakça}

Akgün, Seçil, Kendi Kaynaklarından Amerikalı Misyonerlerin Türk Sosyal Yaşamına Etkisi (1820-1914). X. Türk Tarih Kongresi'nden Ayrı Basım, TTK Basımevi, Ankara 1994.

Barton, James L., Daybreak in Turkey, The Pilgrim Press, Boston 1908.

Bozan, Oktay, "Osmanlı Döneminde Amerikan Misyonerlerinin Diyarbakır Vilayeti 'ne Gelişi ve Faaliyetleri”, Dicle Üniversitesi Sosyal Bilimler Enstitüsü Dergisi, 7, (13), Nisan, 2015, ss. 333-361.

Danacıoğlu, Esra, “Diyarbakır'da Amerikan Misyonerleri”, Diyarbakır: Müze Şehir, (Haz. Ş. Beysanoğlu-M. S. Koz-E. N. İşli), Yapı Kredi Yayınları, İstanbul 1999, ss. 165-175.

Eddy, David B., What next in Turkey Glimpses of the American Board's Work in the Near East. The American Board, Boston: Mass. 1913.

Grabill, Joseph L., Protestant Diplomacy and the Near East, University of Minnesota Press, Minneapolis 1971. 
J. H. Franklin, Ministers of mercy, Pilgrim Press, New York 1919.

Kocabaşoğlu, Uygur, Anadolu'daki Amerika, İmge Kitabevi, Ankara 2000.

Resul, Çatalbaş, Diyarbakır'da Misyonerlik Faaliyetlerinin Tarihi, İstanbul Üniversitesi İlahiyat Fakültesi Dergisi, 29, 2013, ss. 109-132.

Richter, Julius, A History of Protestant Missions in the Near East, London 1910.

Stone, Frank Academies for Anatolia, University Press of America, London 1984.

Taşkın, Faruk, Kendi Kaynaklarında Amerikan Board'ın Türkiye'deki Sağlık Faaliyetleri (1833-1923), Mersin Üniversitesi Sosyal Bilimler Enstitüsü Yayınlanmamış Doktora Tezi, Mersin 2015.

Yıldız, Hatip "II. Abdülhamit Döneminde Diyarbakır Vilayetinde Açılan Yetimhaneler ve Vali Mehmed Halid Beyin Vilayette Misyonerliği Önleme Çabaları" Dicle Üniversitesi Ziya Gökalp Eğitim Fakültesi Dergisi, 14, 2010, ss. 103-118.

\section{Amerikan Board Katalogları ve Bültenleri?}

The American Board of Commissioners for Foreign Missions, the Year Past and The Year to Came, Report of the Prudential Committee for the Home Department, 1908-1909, Boston 1909.

The Nursing in Mission Stations, “Trained Nurses Needed Immediately for Rlissionarp Service”, The American Journal of Nursing, Vol. 11, No. 3. (Dec., 1910), 190-191.

The One Hundred and Fifth Annual Report of the American Board of Commissioners for Foreign Missions, Together with the Minutes of the Meeting Held at Nev Haven, Connecticut, October 26, Boston 1915.

The One Hundred and Third Annual Report of the American Board of Commissioners for Foreign Missions, Together with the Minutes of the Meeting Held at Kansas City, Missouri October 26-28, Boston 1913.

The Orient, "Medical Missionary Work”, vol. IX. Extra Bible House, March 8, Constantinople 1922.

\section{Amerikan Board Arşivi (ABA) İstanbul}

ABA, ABCFM (1917-1922), 1921 No: 086.

ABA, ABCFM (1917-1922), 1921, No: 086.

ABA, Memorial Record for Augustus Walker, an Employee of the American Board, İstanbul. 
ABA, Memorial Record for David H. Nutting, an Employee of the American Board, İstanbul.

ABA, Memorial Record for Edwin S. Ward, an Employee of the American Board, İstanbul.

ABA, Memorial Record for George W. Dunmore, an Employee of the American Board, İstanbul.

ABA, Memorial Record for Henry B. Haskel, an Employee of the American Board, İstanbul.

\section{ABCFM Mikrofilm Arşivi (American Board of Commissioners for Foreign Missions)}

Reel 703, No: 480. Reel 703, No: 481. Reel 703, No: 482. Reel 703, No: 483. Reel 703, No: 484. Reel 706, No: 486.

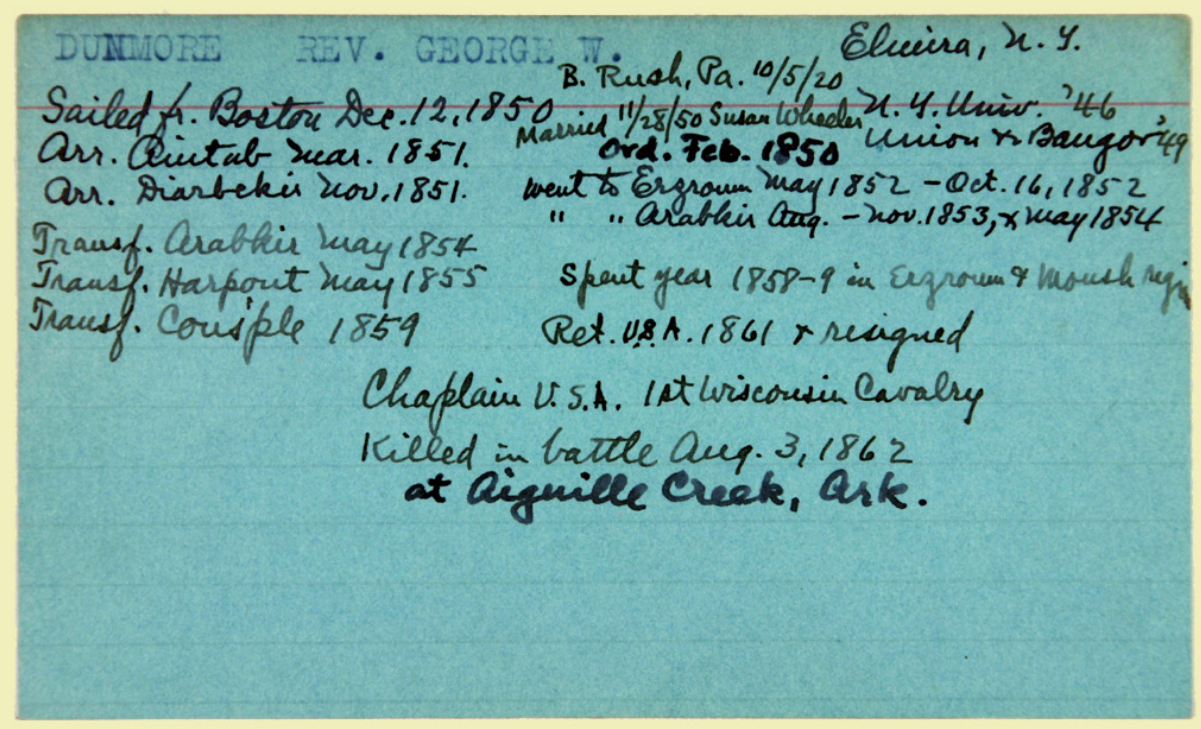

George W. Dunmore

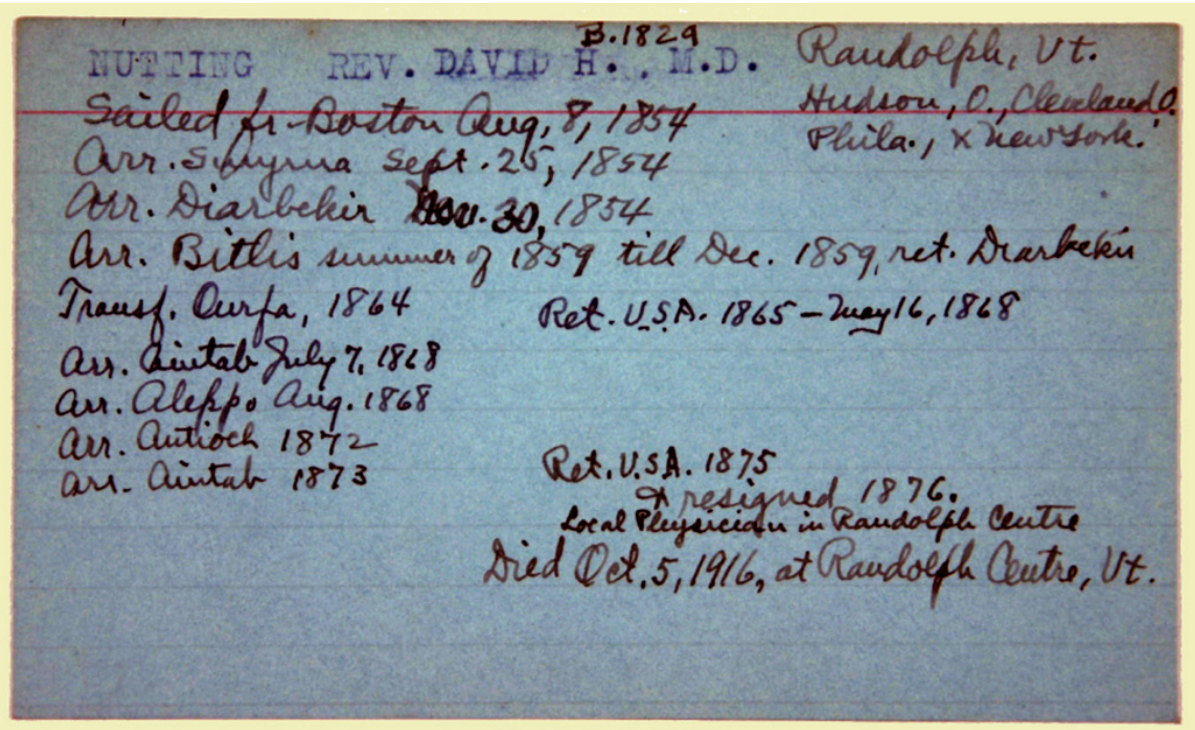

Dr. David H. Nutting 